\title{
Prevalence and risk factors of myopia amongst Grade 8 learners in the Vhembe district, South Africa
}

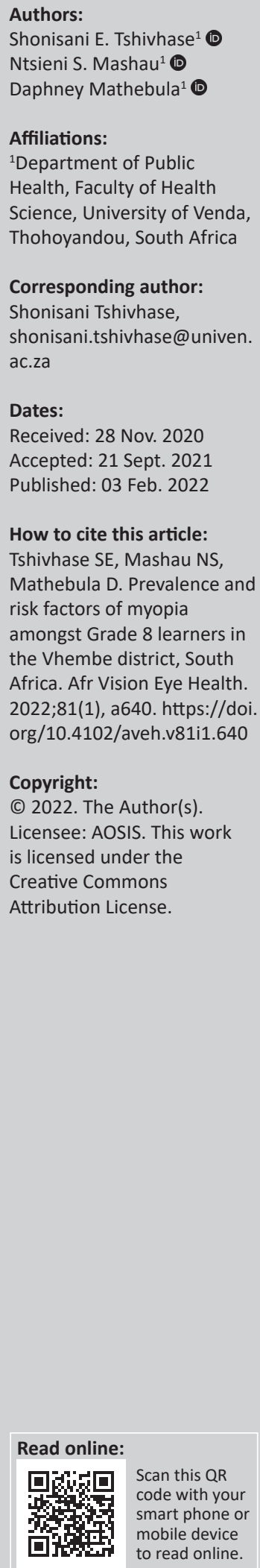

Background: Myopia is the most common cause of refractive errors in both adults and children in many countries. However, it is not a simple refractive error but sometimes an eyesight-threatening disorder. The disorder has a great impact on public health and the socio-economic well-being of people, particularly children.

Aim: The study aimed to assess the prevalence of myopia amongst secondary school learners.

Setting: The study was conducted in the Vhembe District, South Africa.

Methods: A cross-sectional study was carried out amongst 297 Grade 8 students of 13 to 14 years of age. The students were selected using a multi-stage-stratified cluster sampling technique from three secondary schools. Two public secondary schools and one private secondary school. The learners' socioeconomic background, type of school and parental myopia were assessed by a questionnaire before visual acuity assessment. Learners with visual acuity of less than or equal to 6/12 in the worse eye, who showed vision improvement with pinhole, underwent non-cycloplegic retinoscopy and subjective refraction were selected. Myopia was defined as a spherical equivalent of less than or equal to -0.50 dioptre (D). Data were analysed using descriptive statistics.

Results: A total of 289 learners completed the study (156 aged 14 years and 133 aged 13 years). A total of 30 learners were identified to have myopic refractive error making the prevalence of $10.4 \%$. Of the 154 females, $14(47.0 \%)$ had myopia, whilst $16(53.0 \%)$ of the 135 males had myopia making males slightly more myopic than females. From the total learners diagnosed to have refractive error $(n=40)$, myopia constituted $30 / 40(75.0 \%)$ of the learners indicating that it is the commonest type of refractive error amongst secondary learners. Myopia was more common amongst older age children (14 years; $57.0 \%)$. About $18(60.0 \%)$ participants were from the urban area. A total of $17(57 \%)$ of the myopic learners attended private school and about $63 \%$ of the participants' parents were myopic.

Conclusion: Spending more time indoor and continuous reading without resting are risk factors of myopia whilst increased outdoor activities were observed as protective environmental factors against myopia in secondary school learners. Doing more outdoors activities may be beneficial to protect against myopia onset.

Keywords: learners; myopia; prevalence; risk factors; refractive error.

\section{Introduction}

Uncorrected refractive error is a public health problem throughout the world, regardless of age, sex and race. ${ }^{1}$ Studies indicate that almost $52.9 \%$ of visual impairment in 2013 was because of refractive errors, making this a global visual health challenge. ${ }^{2}$ Epidemiological studies have reported differences in the prevalence of refractive error. The reasons for these differing estimates include differences in age, race and ethnicity of the populations studied. Several authors defined myopia as spherical equivalent refraction $(\mathrm{SER}) \leq-0.50$ dioptre (D) in the poorer eye, and was sub-classified as low (SER $<-0.50 \mathrm{D}>-3.00 \mathrm{D})$, medium (SER $<-3.00 \mathrm{D}>-6.00 \mathrm{D})$ and high $(\mathrm{SER}<$ -6.00 D). ${ }^{3,4,5}$ Myopia is the most common cause of refractive errors in most countries. ${ }^{6}$ Thus, it is expected that by 2060 , there will be an increase of about $26 \%$ in the number of children with visual disabilities. This will have a negative impact on their educational and psychosocial development. ${ }^{1,2,7}$ There are over 80 million reported cases of myopic children worldwide, leading to considerable socio-economic and public health problems. ${ }^{8}$ Moreover, high myopia is associated with potentially blinding complications, such as glaucoma, retinal detachment and myopic macular degeneration. ${ }^{4}$ More than 2.3 billion people worldwide suffer from poor vision because of uncorrected refractive error. ${ }^{9}$ About 640 million people are visually impaired from myopia. Most of these people do not 
have access to corrective treatment such as spectacles, contact lenses or refractive surgery. Evidence is mounting to prove that myopia is increasing around the world. Recent studies estimate that about $30 \%$ of the world is currently myopic, and by 2050 almost $50 \%$ of the population will be myopic. ${ }^{10}$ Significantly, developed countries such as South Korea, Taiwan, Singapore, China and Japan are still reporting a high prevalence of myopia between $80 \%$ and $90 \%$. There is an increasing rate of the prevalence of myopia (42\%) that almost doubled in three decades in developed countries such as the United States (US). ${ }^{11}$

Socioeconomic status and lifestyle are reported to be the possible causes of the increasing myopia prevalence. Studies indicate that increased near-work activities, such as excessive viewing of television, excessive reading and playing video games that children are exposed to, make them prone to reduced visual acuity. ${ }^{12,13}$ Although genetic factors play a role in the development of myopia, the rapid growth in prevalence is likely attributable to environmental and lifestyle factors. Previous studies suggested an association between myopia and near-work activities, such as studying, reading and screen time amongst children as reported by Holden et al. ${ }^{11}$ Many studies have confirmed that increasing the time spent outdoors reduces the risk of developing myopia and pooled information indicated a $2 \%$ reduced odds of myopia for each additional hour spent outdoors per week. ${ }^{14}$

It is agreed that there is a genetic and environmental interaction that is involved in myopia cases. Furthermore, Dong et al., ${ }^{9}$ pointed out that the process and progression of myopia follow a typical pattern, with normal vision at a young age, starting around school age a myopic shift and rapid increase in myopia begins, which continues until late teenage years. High myopia is associated with significantly increased risks of retinal degeneration and detachment, openangle glaucoma and cataracts at a younger age. ${ }^{15}$ However, these associated conditions have a significant lifetime risk of severe visual impairment, including blindness. As a result of the significant risks associated with the development of high myopia, paediatric ophthalmologists have been very interested in the prevention of myopic progression.

Darko-Tarki et al. ${ }^{16}$ claimed that the idea that close visual work might cause or promote myopia has been mooted for many years. They stated that this causal factor is supported by the well-documented association between short-sightedness and educational attainment. Alrasheed et al. ${ }^{17}$ stated that an uncorrected refractive error creates disadvantages for children's education and employment opportunities, which could seriously affect the quality of their life and productivity, driving them into poverty. Belete et al. ${ }^{18}$ reported that $54.2 \%$ of their study participants had familial myopia. Factors that were found to be positively linked with myopia were family history of myopia, private school learners, longer time spent partaking in indoor activities, shorter walking distance, lack of outdoor sports activities and use of visual display units. Studies confirmed that many school children are exposed to excessive study pressure as they prepare for their examinations, and those in private school are almost three times at risk of developing myopia as compared with those attending public schools. ${ }^{19}$

It is estimated that 225000 people (both children and adults) in South Africa are blind ${ }^{20}$ Furthermore, about $10.0 \%$ of children need refractive services and correction..$^{21}$ In the urban areas, about $60.0 \%$ of the population residing in urban areas had access to eye healthcare, whilst only $30.0 \%$ of those in the rural areas had access to eye healthcare. The prevalence of myopia and hypermetropia amongst South African school children was found to be $4.0 \%$ and $2.6 \%$, respectively. ${ }^{17}$ Therefore, special attention should be given to children of school-going age because refractive error begins at that age. In the Vhembe district, school screening by optometrists and ophthalmic nurses discovered that many children reach their high school level without having had an eye examination. ${ }^{22}$ Many of them reported experiencing difficulties taking notes from the board, especially when sitting in the middle row or at the back in class. The Integrated School Health Programme Fourth Draft (2012) stipulated that all children above 8 years should be screened during their time at school. ${ }^{23}$ Primary healthcare (PHC) nurses conduct daily screenings at primary schools, but high schools have never been screened as the Department of Health seems more concerned with primary school learners. As a result of the unavailability of a myopic prevalence study in the Vhembe District, we decided to investigate the prevalence and risk factors of myopia in the district.

\section{Methodology Study design}

A school-based cross-sectional study was adopted to investigate the prevalence of myopia and the risk factors associated with it amongst Grade 8 learners in the Vhembe District, South Africa.

\section{Study setting}

The study was conducted in Malamulele under the Collins Chabane Local Municipality, which is one of the five local municipalities in the Vhembe District. The area is mostly rural. Of the 45 high schools about 43 of the high schools are public and only two are private. The Vhembe District is relatively poor in terms of resources compared with other districts within the province. This is because it is dominated by rural areas where most of the inhabitants are farm labourers and public service employees. School health services are conducted daily by the PHC nurses. The PHC covers primary schools and focuses on general health.

\section{Study population}

The target population of this study was high school learners from the Malamulele Circuit. The accessible population were all Grade 8 learners from high schools that fall under the selected circuit. Learners who were in 
the academic year 2018/2019 regular programme and who had been selected by the sampling procedure constituted the study population. The study involved both male and female Grade 8 learners. The study population included learners aged between 13 and 14 years from both public and private secondary schools. Learners were excluded if they were not in Grade 8.

\section{Sampling}

In this study, stratified random sampling was used to select secondary schools, which were then classified into three strata - private, urban and rural schools - so that there would be representatives from each stratum or category. A simple random sampling technique was subsequently used to select three schools, one from each stratum. Therefore, one secondary school from Malamulele location (urban), one private school and one school from the central area (rural), in which there were none or limited healthcare services, were selected. The systemic random sampling technique was then applied to select a total of 300 participants based on class registers. Proportional sampling was also used to ensure that the number of participants who were recruited from each Grade 8 was equal to their estimated proportional sizes in the population.

\section{Data collection}

To assure data quality, all the selected schools were visited in advance to seek permission and cooperation from the school governing body and the principals. An invitation to participate in the study was sent to parents or guardians of the recruited study participants, together with the consent forms and information sheets. A meeting between the schoolgoverning body, teachers and parents was held before the survey, where the details of the study were clearly outlined. Participants were included only if their parents gave signed consent forms for an examination.

The work was carried out by a team that comprised an ophthalmic nurse, an optometrist and one person from each school who facilitated data collection. Examinations were performed by optometrists and ophthalmic nurses with good experience in regional surveys. The data collectors were given a one-day training before the actual data collection. Pre-testing of the questionnaires was conducted on $5 \%$ of learners of the secondary school not included in the actual study and necessary corrections were made before the actual data collection. The whole study was conducted on school premises during the school days and school hours. A questionnaire, participant information sheet and written informed consent were administered in the learners' preferred language (Xitsonga or English). A questionnaire and assessment form was used to collect data. The questionnaire, which comprised closed-ended items, was categorised into the following sections: the demographic data, parental myopia and social activities. The assessment form was used for recording the eye examination results and it included variables to measure the learners' visual acuity, refraction and ophthalmoscopy results. Refraction results comprised objective (retinoscopy) and subjective results (the trial frame and lenses were used).

The ophthalmic examinations included distance visual acuity measurement with and without pinhole, noncycloplegic retinoscopic refraction, subjective refraction, ocular alignment and motility evaluation. An ophthalmic nurse measured visual acuity for each eye using the Snellen E-chart hanging on the wall at a distance of $6 \mathrm{~m}$ in a well-lighted classroom. A line of optotypes is generally considered to have been read correctly when more than half of the optotypes presented have been read correctly on the chart. Visual acuity was repeated with a pinhole. Learners with uncorrected and presenting visual acuity of less than or equal to $6 / 12$, whose vision improvement showed with pinhole were refracted by an optometrist using a streak retinoscope and trial lens. Non-cycloplegic retinoscopic refraction was performed in a darkened room by maintaining a 2/3 m distance from the examiner. For those with positive retinoscopic refraction, subjective refraction was performed using a standard refraction trial set and frame and eyeglasses were prescribed. All learners with visual acuity of less than or equal to $6 / 12$ and whose visual acuity did not improve with pinhole were advised to have regular follow-up at a nearby eye care centre for further management. The principal investigators closely monitored the entire process of data collection.

\section{Definitions used}

For this study, the following operational definitions were used:

- Refractive error: Refractive error (RE) was classified based on the spherical equivalent refraction (SER) calculated as the sum of the sphere and half the cylindrical component. $3,4,5$

- The worse eye was defined as the eye with the greater absolute value of the spherical equivalent of the subjective refraction. ${ }^{24.25}$

- Myopia: Myopia was defined as visual acuity of less than or equal to $6 / 12$ in the worse eye that was corrected by a spherical equivalent of $-0.5 \mathrm{D}$ or worse..$^{25}$

- Mild myopia is defined as less than or equal to $-0.50 \mathrm{D}$ and greater than $-3.0 \mathrm{D}$.

- Moderate myopia is defined as less than or equal to $-3.0 \mathrm{D}$ and greater than $-6.0 \mathrm{D}$.

- Severe myopia is defined as less than or equal to $-6.0 \mathrm{D}$.

- The visual acuity test is a measure of the eye's ability to differentiate shapes and details of objects at a certain distance, and it was taken monocularly at $6 \mathrm{~m}$ using the Snellen's acuity chart. ${ }^{25,26}$

\section{Data analysis}

The completed questionnaires were scrutinised after data collection. The researcher used codes rather than respondents' names and checked data by frequency to identify missing or incorrect values. Questionnaires that were not properly 
completed were excluded and all completed questionnaires were collated and coded starting from 001 to 289. Data were then captured into the Statistical Package for Social Sciences (SPSS) software version 26. After cleaning the data, descriptive and frequencies were applied to the data. The data were presented in tables and charts.

\section{Ethical considerations}

Ethical approval to conduct the study was granted by the University of Venda's Research Ethics Committee (reference number: SHS19PH/21/0110). Informed written consent and assent were obtained before examination from the parents and learners, respectively, after adequate information about the study had been provided to them. The study followed the tenets of the Declaration of Helsinki for research involving human subjects. Confidentiality of the respondents' responses was maintained by removing their names from the questionnaire. Learners were informed about the purpose of the study and assured that their responses would be treated confidentially. Participants were also informed that their participation was entirely voluntary and that they were free to withdraw if they felt uncomfortable.

\section{Results}

Of the 300 Grade 8 learners randomly recruited from secondary schools under Malamulele circuit, 297 (99\%) participated in the study. However, only 289 (96.3\%) learners with completed relevant data were included for analysis. The study sample comprised 154 (53\%) females and 135 (47\%) males. A total of $156(54 \%)$ of the participants were 14 years old, whilst $133(46 \%)$ were 13 years old. Most study participants $(85 \%, n=245)$ were from public schools. The majority of the participants $(78 \%, n=225)$ were from the rural area as compared with urban areas $(22 \%, n=64)$. A significant number of the parents of the participants 199 (69\%) were unemployed. All (100\%) of the participants were from Grade 8 as shown in Table 1.

Of the 289 learners who participated in this study, 47 (16\%) had a visual acuity of $6 / 12$ or worse at least in one eye. The underlying causes for visual impairment were refractive error at $40(85 \%)$ followed by corneal problems at $4(8.5 \%)$ and lens problems at $3(6.4 \%)$. Amongst the participants with refractive error, myopia constituted 30 (75\%) followed by hyperopia and astigmatism at 7 (18\%) and 3 (7.5\%), respectively (see Figure 1).

The overall prevalence of myopia was $10.4 \%$ in our study, of which more than or $17(57 \%)$ of the participants had moderate myopia followed by mild and severe myopia at $11(3.7 \%)$ and $2(7 \%)$, respectively (see Figure 2$)$.

The prevalence of myopia was 19\% $(n=63)$ for participants with myopic parents whilst those without myopic parents stand at $11(37 \%)$ (Table 2). Myopia prevalence was high amongst the 14 years at $17(57 \%)$ than the 13 years at $13(43 \%)$.
TABLE 1: Demographic characteristics of participants $(N=289)$.

\begin{tabular}{llcc}
\hline Variable & Category & Frequency & Percentage \\
\hline Gender & Female & 154 & 53 \\
& Male & 135 & 47 \\
Age & 13 years & 133 & 46 \\
& 14 years & 156 & 54 \\
Grade & 8 & 289 & 100 \\
Type of residential area & Rural & 225 & 78 \\
& Urban & 64 & 22 \\
Type of school & Public & 245 & 85 \\
& Private & 44 & 15 \\
\hline
\end{tabular}

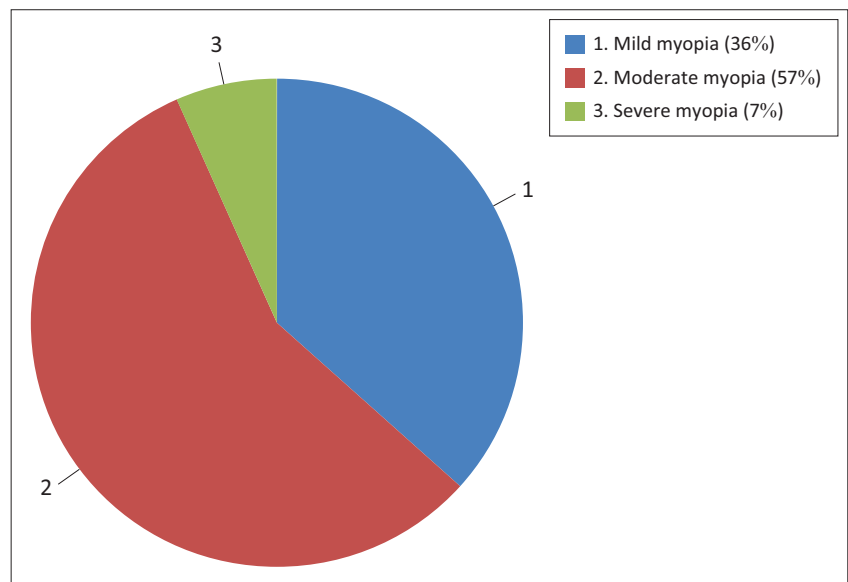

FIGURE 1: Distribution of refractive errors in the study.

The percentage of myopia in male participants was slightly higher $16(53 \%)$ than in female participants $14(47 \%)$. About $18(60 \%)$ participants were from the urban area. A total of $17(57 \%)$ of the myopic participants were attending private school. About $63 \%$ of the participants' parents were myopic.

The majority $(73 \%, n=22)$ of the myopic participants indicated that they do not take a break after reading for more than $30 \mathrm{~min}$. Most $(70 \%, n=21)$ participants with myopia spent less than $2 \mathrm{~h}$ per day doing outdoor activities as shown in Table 1 . The percentage of participants who spent more time performing near-work activities was marginally higher 16 (57\%) as compared with those spending less time doing near-work activities as shown in Table 2.

\section{Discussion}

Myopia is considered an important public health problem and a common cause of visual impairment throughout the world. Its prevalence varies by country, age and ethnic group organisation. ${ }^{27}$ Although school screening has been performed elsewhere, the study on the prevalence of myopia and its associated risk factors amongst secondary school students in the Malamulele community was the first of its kind. The overall prevalence of myopia was found to be $10.4 \%$, with visual acuity of $6 / 12$ or less in the worst eye and a spherical equivalent power of $-0.50 \mathrm{D}$ or below. This can be attributed to the study population in this study as compared with other studies. It is well established that myopia is highly prevalent in adolescents as compared with other age groups. ${ }^{28}$ The present study's findings 
TABLE 2: The prevalence of myopia and its association with the factors studied.

\begin{tabular}{|c|c|c|c|c|c|}
\hline \multirow[t]{2}{*}{ Characteristics } & \multirow[t]{2}{*}{ Characteristic } & \multicolumn{2}{|c|}{ Myopia $(n=30)$} & \multicolumn{2}{|c|}{ Myopia percentage of total sample $(n=289)$} \\
\hline & & $n$ & $\%$ & $n$ & $\%$ \\
\hline \multirow[t]{2}{*}{ Gender } & Male & 16 & 53 & 16 & 5.5 \\
\hline & Female & 14 & 47 & 14 & 5.0 \\
\hline \multirow[t]{2}{*}{ Age } & 13 years & 13 & 43 & 13 & 4.4 \\
\hline & 14 years & 17 & 57 & 17 & 6.0 \\
\hline Residents of learner & Rural & 12 & 40 & 12 & 4.1 \\
\hline \multirow[t]{2}{*}{ Type of school } & Public & 13 & 43 & 13 & 4.4 \\
\hline & Private & 17 & 57 & 17 & 6.0 \\
\hline \multirow[t]{2}{*}{ Parental myopia } & Yes & 19 & 63 & 19 & 6.6 \\
\hline & No & 11 & 37 & 11 & 3.8 \\
\hline \multirow{2}{*}{$\begin{array}{l}\text { Uses of computer and smartphone (how many } \\
\text { hours per day) }\end{array}$} & Less than $2 \mathrm{~h}$ & 12 & 40 & 12 & 4.1 \\
\hline & More than $2 \mathrm{~h}$ & 18 & 60 & 18 & 6.2 \\
\hline Time spent doing outdoor activities & Less than $2 \mathrm{~h}$ & 21 & 70 & 21 & 7.3 \\
\hline \multirow[t]{2}{*}{ Takes break after 30 minutes of reading } & Yes & 8 & 27 & 8 & 3.0 \\
\hline & No & 22 & 73 & 22 & 7.6 \\
\hline \multirow[t]{2}{*}{ Time spent doing near work } & Less than $2 \mathrm{~h}$ & 14 & 47 & 14 & 5.0 \\
\hline & More than $2 \mathrm{~h}$ & 16 & 53 & 16 & 5.5 \\
\hline
\end{tabular}

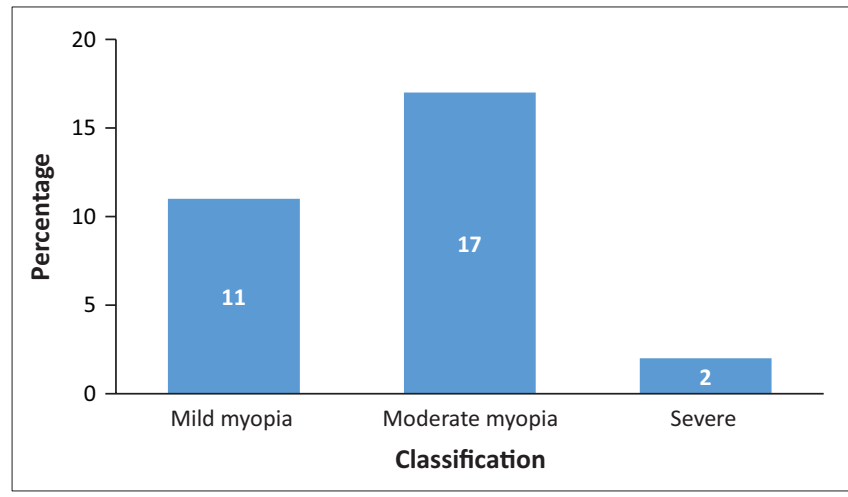

FIGURE 2: Magnitude of myopia in the study setting.

regarding myopia prevalence were higher than the study findings reported in countries such as Kenya (7.5\%), Ethiopia (6.5\%), Nigeria (2.7\%) and also Durban in South Africa (2.9\%), but lower than studies conducted in other countries..$^{4,25,29,30,31}$ However, the variation in this study could be because of the difference in lifestyle, sample size, examination technique used and genetic background.

Most of the study participants came from rural areas because the Vhembe district is mostly rural. Most secondary schools were also found in a rural area with few schools found in the urban area. Hung et al. ${ }^{32}$ reported similar findings of the study that was conducted in the rural area of Vietnam. This study found that myopia was most prevalent in students who come from urban areas and attend private schools as compared with students who come from a rural area and attend public schools. These results are similar to a recent study by Xie et al., ${ }^{33}$ which found a higher prevalence of myopia in urban areas as compared with the rural areas. Ragot et al. ${ }^{28}$ also reported another study that disclosed that the prevalence of childhood myopia is lowest $(6.9 \%)$ in the outer suburban region and highest (17.8\%) in the inner-city region. The reason for the high prevalence of myopia in learners from the urban area might have been attributed to the high rise in technology and the increased usage of mobile phones, tablets, computers and televisions. Similarly, children in urban areas are involved more in indoor and near-work activities, such as higher usage of computers, smartphones and video games unlike children from rural areas as reported by Atowa et al..$^{29}$ in their study. The findings from this study showed that myopic learners spent more time performing indoor activities such as reading and less time in outdoor activities than the non-myopic learners. Studies have confirmed that reduction in outdoor activities has been found to have some influence on the onset, development and progression of myopia. ${ }^{28,34}$

Regarding gender, the present study found that the prevalence of myopia was slightly higher in males than in females (Table 2), similar results were also reported by Ragot et al. ${ }^{28}$ who mentioned that myopia was slightly more (52.7\%) prevalent in males as compared with females (47.3\%). However, several studies reported a higher prevalence of myopia in females than in males..$^{29,32,33}$ However, it differs from the study conducted in Welkite town (Ethiopia) and Shanghai (China) that revealed that sex had no association with the prevalence of myopia. ${ }^{25,35}$ The reason may be that the cause of myopia could be more hereditary in our study area. Other studies further confirmed that girls experienced more risk factors of developing myopia as compared with boys, the reason possibly being that girls study harder and participate less in outdoor activities than boys. ${ }^{32,36 .}$

In this study, a high prevalence of myopia was associated with higher age and higher grade level, even though this study was only performed with Grade 8 learners. Also, the stage of puberty might be a major contributing factor to myopia development and progression in this study.

This study was consistent with the study findings conducted in Vietnam, Abia state (Nigeria) and Welkite town (Ethiopia), which reported a similar trend that the 
prevalence of myopia amongst school children tends to increase with age. ${ }^{25,32,33}$

Concerning the parental history of myopia the study showed that a high prevalence of myopia was found amongst students where either parent had myopia. Students whose parents had myopia had a high risk of having myopia as compared with those whose parents did not have myopia. It is believed that myopia is caused by a combination of genetic factors and environmental factors. ${ }^{1}$ Also, the effects of habits and lifestyles cannot be overlooked because myopic parents could share the same environment as their children. The study results concur with the findings of Huang et al., ${ }^{30}$ and Hung et al., ${ }^{32}$ who reported that myopic parents were found to be associated with an increased incidence of having myopia in their children. Yang et al., ${ }^{38}$ further attested that when one parent was myopic, the child was 2.52 times more likely to develop myopia compared with a child with two non-myopic parents. The study further mentioned that children whose parents had university degrees were more likely to develop myopia as the mothers may pressurise their children to study harder than children whose parents had primary school education. However, our findings differ from the study results conducted in India by Saxena et al., ${ }^{39}$ who reported that the prevalence of myopia in children from high socioeconomic status is higher than those from the low socio-economic status.

With regard to lifestyle, the present study agrees with the study's findings carried out by Peregrina et al., ${ }^{1}$ who indicated that myopic children spend around $0.95 \mathrm{~h}$ per day in front of a computer as opposed to non-myopic children. Our study's findings revealed that myopic students spend 30-40 min of continuous reading without resting their eyes. Furthermore, several studies confirm the findings that there is an association between myopia and time spent on studying or doing near-work activities. ${ }^{32,37,40}$ However, Rose et al., ${ }^{41}$ and Lin et al., ${ }^{42}$ have pointed out that near-work activities are not at risk factors in the development of myopia.

Regarding time spent indoor, the study found that spending more than $2 \mathrm{~h}$ per day on outdoor activities was associated with less myopic children. High number of myopic children spent less than $2 \mathrm{~h}$ per day doing outdoor activities. This can be because of the increased usage of mobile phones, tablets, computers and watching television. This and the reduction of outdoor activities have been found to influence the onset and progression of myopia. Similar results were reported in Spain in 2019 and Xiamen (China), where children spend less than $2 \mathrm{~h}$ on outdoor activities and more hours are spent on nearwork activities such as using of smartphones and other electronic devices. ${ }^{43}$ In addition, the Sydney study on myopia reported that spending more time on outdoor activities was associated with less myopia in children and it significantly reduced myopia progression.

\section{Limitations}

The use of the non-cycloplegic refraction data collection method was selected to avoid the potential side effects of Mydriacyl that might affect student learning. Therefore, non-cycloplegic refraction might have increased the rate of pseudo myopia that might have led to the underestimation of myopia prevalence in our study. The study was not completely reflective of the population in the Vhembe district because only Grade 8 learners under the selected schools of the Malamulele circuit were assessed. The parental history of myopia was obtained using reported questionnaires, this method could be subjected to information bias. The sample might have been subjected to selection bias. Lastly, future studies are needed on a large population of secondary students in different grades to determine the risk factors.

\section{Conclusion}

This study demonstrated that there is a low prevalence of myopia amongst learners of Grade 8 in the Vhembe District. The following conclusions were drawn from the study. The study found that myopia is more common amongst males than in females. Participants who spent a lot of time doing indoor activities such as reading and watching television are at risk of developing myopia. Additionally, family history is a risk factor for myopia, as all the participants who had one or both parents with myopia also had myopia.

\section{Recommendation}

Based on the study's findings, the researchers recommend that more eye health education be conducted by the Department of Health in the Malamulele community. The study's findings demonstrate that exercise may be a modifiable risk factor that could represent a future target for public health interventions to curb the progression of myopia. Given that these findings, which are consistent with prior studies that have identified a protective effect of time outdoors and sports participation, exercise can be a cornerstone of healthy lifestyle practices and is already being encouraged through multiple widespread public health campaigns and health talks in children and the community.

\section{Acknowledgements}

This work was supported by the University of Venda Research and Innovation Directorate.

\section{Competing interests}

The authors declare that they have no financial or personal relationships that may have inappropriately influenced them in writing this article.

\section{Authors' contributions}

S.E.T., N.S.M. and D.M. contributed equally to this work. 


\section{Funding information}

This research received no specific grant from any funding agency in the public, commercial or not-for-profit sectors.

\section{Data availability}

Derived data supporting the findings of this study are available from the corresponding author, S.E.T., on request.

\section{Disclaimer}

The views and opinions expressed in this article are those of the authors and do not necessarily reflect the official policy or position of any affiliated agency of the authors, and the publisher.

\section{References}

1. Alvarez-Peregrina CC, Sanchez-Tena MA, Martinez-Perez CC, Villa-Collar CC Prevalence and risk factors of myopia in Spain. J. Ophthalmol. 2019 Aug 18;2019. https://doi.org/10.1155/2019/3419576

2. Peltzer K, Phaswana-Mafuya N, Arokiasamy $P$, et al. Prevalence, circumstances and consequences of non-fatal road traffic injuries and other bodily injuries among older people in China, Ghana, India, Mexico,
African Safety Promotion Journal. 2015;13(2):59-77.

3. Junghans BM, Crewther SG. Prevalence of myopia among primary school children in eastern Sydney. Clin Exp Opt. 2003;86(5):339-345. https://doi. org/10.1111/j.1444-0938.2003.tb03130.x

4. Naidoo KS, Raghunandan A, Mashige KP, et al. Refractive error and visual impairment in African children in South Africa. Investig. Ophthalmos. Vis. Sci. 2003;44(9):3764- 3770. https://doi.org/10.1167/iovs.03-0283

5. Mashige KP, Jaggernath J, Ramson P, Martin C, Chinanayi FS, Naidoo KS. Prevalence of refractive errors in the INK area, Durban, South Africa. Optom Vis Sci. 2016;93(3):243-250. https://doi.org/10.1097/OPX.0000000000000771

6. Khoshhal F, Hashemi $\mathrm{H}$, Hooshmand $\mathrm{E}$, et al. The prevalence of refractive errors in the Middle East: a systematic review and meta-analysis. Int. Ophthalmol. 2020(6):1571-1586. https://doi.org/10.1007/s10792-020-01316-5

7. Joseph $\mathrm{S}$, Krishnan $\mathrm{T}$, Ravindran RD, et al. Prevalence and risk factors for myopia and other refractive errors in an adult population in southern India. Ophthalmic Physiol Opt. 2018;38(3):346-358. https://doi.org/10.1111/opo.12447

8. Rudnicka AR, Kapetanakis VV, Wathern AK, et al. Global variations and time trends in the prevalence of childhood myopia, a systematic review and quantitative meta-analysis:Implications for aetiology and early prevention. Br Ophthalmol. 2016;100(7):882-890. https://doi.org/10.1136/bjophthalmol-2015-307724

9. Dong YH, Liu HB, Wang ZH, Xu RB, Yang ZP, Ma J. The epidemic status and secular trends of myopia prevalence for Chinese children and adolescents aged 7-18 years from 2005 to 2014. Zhōnghuá Yù Fáng Yī Xué Zá Zhì [Chinese Journal of Preventive Medicine]. 2017;51(4):285-289. https://doi.org/10.3760/ cma.j.issn.0253-9624.2017.04.002

10. Dolgin E. The myopia boom. Nature. 2015;519(7543):276-278. https://doi. org/10.1038/519276a

11. Holden BA, Fricke TR, Wilson DA, et al. Global prevalence of myopia and high myopia and temporal trends from 2000 through 2050. J. Ophthalmol. 2016 May 1;123(5):1036- 1042. https://doi.org/10.1016/j.ophtha.2016.01.006

12. Ichhpujani P, Singh RB, Foulsham W, Thakur S, Lamba AS. Visual implications of digital device usage in school children: A cross-sectional study. BMC Ophthalmol. 2019:76. https://doi.org/10.1186/s12886-019-1082-5

13. Lanca C, Saw SM. The association between digital screen time and myopia: A systematic review. Ophthalmic Physiol Opt. 2020;40(2):216-229. https://doi. org/10.1111/opo.12657

14. Wong YL, Saw SM. Epidemiology of pathologic myopia in Asia and worldwide. Asia Pac J Ophthalmol (Phila). 2016;5(6):394-402. https://doi.org/10.1097/ APO.0000000000000234

15. Schaeffel F, Feldkaemper M. Animal models in myopia research. Clin Exp Optom. 2015;98(6):507-517. https://doi.org/10.1111/cxo.12312

16. Darko-Takyi C, Owusu-Ansah A, Appiah-Eduenu C, Abu EK, Boadi-Kusi SB, Osei-Akoto Y. Refractive and binocular vision status of optometry students, Ghana. J Medical Biomed Sci. 2016;5(2):24-29. https://doi.org/10.4314/jmbs.v5i2.4

17. Alrasheed SH, Naidoo KS, Clarke-Farr PC. Prevalence of visual impairment and refractive error in school-aged children in South Darfur State of Sudan. Afr Vision Eye Health. 2016;75(1):1-9. https://doi.org/10.4102/aveh.v75i1.355

18. Belete GT, Anbesse DH, Tsegaye AT, Hussen MS. Prevalence and associated factors of myopia among high school students in Gondar town, northwest Ethiopia, 2016. Clin Optom (Auckl). 2017;11-18. https://doi.org/10.2147/OPTO. S120485
19. Morgan IG, French AN, Ashby RS, et al. The epidemics of myopia: Aetiology and prevention. Prog. Retin. Eye Res. 2018;62:134-149. https://doi.org/10.1016/j. preteyeres.2017.09.004

20. Sithole HL. A critical analysis of the South African health policies and programmes with regard to eye health promotionLawrence Sithole. Eur. J. Public Health. 2014;24(suppl_2). https://doi.org/10.1093/eurpub/cku165.119

21. Sewunet SA, Aredo KK, Gedefew M. Uncorrected refractive error and associated factors among primary school children in Debre Markos District, northwest Ethiopia. BMC Ophthalmol. 2014:14(1):1-6. https://doi.org/10.1186/1471-241514-95

22. Sibiya N, Netshikweta L, Kgole J, Stellenberg E, Seekoe E, Klopper HC. Community engagement by university nursing schools: Survey and case studies. Trends in Nursing. 2013;2(1):101-123. https://doi.org/10.14804/2-1-39

23. Kohl 3rd HW, Craig CL, Lambert EV, et al. The pandemic of physical inactivity: Global action for public health. Lancet. 2012;380(9838): 294-305. https://doi. org/10.1016/S0140-6736(12)60898-8

24. Choi JA, Han K, Park YM, La TY. Low serum 25-hydroxyvitamin D is associated with myopia in Korean adolescents. Invest Ophthalmol Vis Sci. 2014:55(4):2041- 2047. https://doi.org/10.1167/iovs.13-12853

25. Gessesse SA, Teshome AW. Prevalence of myopia among secondary schoo students in Welkite town: South-Western Ethiopia. BMC Ophthalmol. 2020;20(1):1-6. https://doi.org/10.1186/s12886-020-01457-2

26. Marsden J, Stevens S, Ebri A. How to measure distance visual acuity. Community Eye Health. 2014;27(85):16.

27. Ghaderi S, Hashemi $H$, Jafarzadehpur $E$, et al. The prevalence and causes of visual impairment in seven-year-old children. Clin Exp Optom. 2018;101(3):380-385. https://doi.org/10.1111/cxo.12646

28. Ragot A, Baraza M, Clarke-Farr P. Prevalence of myopia and its socio-demographic distribution amongst secondary school going adolescents in Lurambi Sub-County, Kakamega, Kenya. J. Ophthalmol. 2020;5:64-70. https://doi.org/10.5603/ OJ.2020.0015

29. Atowa UC, Munsamy AJ, Wajuihian SO. Prevalence and risk factors for myopia among school children in Aba, Nigeria. Afr Vision Eye Health. 2017;76(1):1-5. https://doi.org/10.4102/aveh.v76i1.369

30. Huang L, Kawasaki H, Liu Y, Wang Z. The prevalence of myopia and the factors associated with it among university students in Nanjing: A cross-sectional study. Medicine. 2019;98(10):e14777. https://doi.org/10.1097/MD.0000000000014777

31. Das A, Dutta H, Bhaduri G, De Sarkar A, Sarkar K, Bannerjee M. A study on refractive errors among school children in Kolkata. J. Indian Med. Assoc. 2007;105(4):169-172.

32. Hung HD, Chinh DD, Van Tan P, et al. The Prevalence of myopia and factors associated with it among secondary school children in rural Vietnam. Clin Ophthalmol (Auck). 2020;14:1079-1090. https://doi.org/10.2147/OPTH.S251218

33. Xie Z, Long $Y$, Wang J, Li Q, Zhang Q. Prevalence of myopia and associated risk factors among primary students in Chongqing: multilevel modeling. BMC Ophthalmol. 2020;20(1):1-28. https://doi.org/10.1186/s12886-020-01410-3

34. Deng L, Pang Y. Effect of outdoor activities in myopia control: meta-analysis of clinical studies. Optom Vis Sci. 2019;96(4):276-282. https://doi.org/10.1097/ OPX.0000000000001357

35. Wang, X., Dong, J. and Wu, Q., 2016. Refractive status of primary, middle and senior high school students in Shanghai. Int J Opthalmol Eye Res. 6(001).1-3. https://doi.org/10.19070/2332-290X-SI06001

36. Paudel $P$, Ramson $P$, Naduvilath $T$, et al. Prevalence of vision impairment and refractive error in school children in Ba Ria - Vung Tau province, Vietnam. Clin.

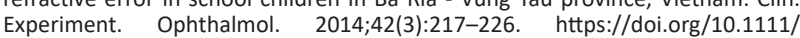
ceo.12273

37. Guo L, Yang J, Mai J, et al. Prevalence and associated factors of myopia among primary and middle school-aged students: A school-based study in Guangzhou. Eye. 2016;30(6):796-804. https://doi.org/10.1038/eye.2016.39

38. Yang M, Luensmann D, Fonn D, et al. Myopia prevalence in Canadian schoo children: A pilot study. Eye. 2018 Jun;32(6):1042-1047. https://doi. org/10.1038/s41433-018-0015-5

39. Saxena R, Vashist $P$, Tandon $R$, et al. Prevalence of myopia and its risk factors in urban school children in Delhi: The North India Myopia Study (NIM Study). Plos One. 2015;10(2):e0117349. https://doi.org/10.1371/journal.pone.0117349

40. French AN, Morgan IG, Mitchell P, Rose KA. Risk factors for incident myopia in Australian schoolchildren: The Sydney Adolescent Vascular and Eye Study. J. Ophthalmol. 2013;120(10):2100-2108. https://doi.org/10.1016/j.ophtha. 2013.02.035

41. Rose KA, Morgan IG, Ip J, et al. Outdoor activity reduces the prevalence of myopia in children. J. Ophthalmol. 2008;115(8):1279-1285. https://doi.org/10.1016/j. ophtha.2007.12.019

42. Ramamurthy D, Lin Chua SY, Saw SM. A review of environmental risk factors for myopia during early life, childhood and adolescence. Clin Exp Optom. 2015;98(6):497-506. https://doi.org/10.1111/cxo.12346

43. He $M$, Zheng $Y$, Xiang F. Prevalence of myopia in urban and rural children in mainland China. Optom Vis Sci. 2009;86(1):40-44. https://doi.org/10.1097/ OPX.0b013e3181940719 